\title{
When Orexins Meet Cannabinoids: Bidirectional Functional Interactions
}

Fernando Berrendero ${ }^{1,2^{*}}$, África Flores ${ }^{3}$ and Patricia Robledo ${ }^{4 *}$

${ }^{1}$ Faculty of Experimental Sciences, Universidad Francisco de Vitoria, UFV, 28223 Pozuelo de Alarcón, Madrid, Spain

${ }^{2}$ Laboratory of Neuropharmacology, Department of Experimental and Health Sciences, Universitat Pompeu Fabra, PRBB, 08003 Barcelona, Spain

${ }^{3}$ Institute of Neurosciences, Autonomous University of Barcelona, 08193 Bellaterra, Barcelona, Spain

${ }^{4}$ Integrative Pharmacology and Systems Neuroscience, IMIM-Hospital del Mar Medical Research Institute, Barcelona, Spain

*Corresponding authors: Fernando Berrendero, Faculty of Experimental Sciences, Universidad Francisco de Vitoria, UFV, 28223 Pozuelo de Alarcón, Madrid, Spain, Email: fernando.berrendero@ufv.es; Patricia Robledo, Integrative Pharmacology and Systems Neuroscience, IMIM-Hospital del Mar Medical Research Institute, Barcelona, Spain, E-mail: probledo@imim.es. 


\begin{abstract}
A growing body of evidence suggests the existence of biochemical and functional interactions between the endocannabinoid and orexin systems. Cannabinoid and orexin receptors have been shown to form heterodimers in agreement with the overlapping distribution of both receptors in several brain areas, and the activation of common intracellular signaling pathways, such as the MAP kinase cascade. The activation of orexin receptors induces the synthesis of the endocannabinoid 2-arachidonoyl glycerol suggesting that the endocannabinoid system participates in some physiological functions of orexins. Indeed, functional interactions between these two systems have been demonstrated in several behavioral responses including nociception, reward and food intake. The present review is focused on the latest developments in cannabinoidorexin cross-modulation and the implications of this interesting interaction.
\end{abstract}

Keywords: cannabinoid, orexin, heterodimers, reward, nociception, feeding 


\section{The endocannabinoid and orexin systems}

The endocannabinoid system (ECS) consists of two main endogenous ligands: anandamide (AEA) and 2-arachidonoylglycerol (2-AG) called endocannabinoids, the synthetizing enzymes: diacylglycerol lipase- $\alpha$ (DAGL) and Nacylphosphatidylethanolamine-phospholipase D (NAPE-PLD), the degradation enzymes: fatty acid amide hydrolase (FAAH) and monoacylglycerol lipase (MAGL), and two major G protein-coupled receptors (GPCR): the cannabinoid type 1 (CB1R) and type $2(\mathrm{CB} 2 \mathrm{R})$ receptors. Other putative cannabinoid receptors have been described including the vanilloid type 1 receptor (TRPV1) [1], and the G protein-coupled receptor 55 (GPR55) [2]. Endocannabinoids are lipid signaling molecules that display distinct pharmacological profiles, as well as regional diversity [3]. Different to most neurotransmitters, they are not stored in presynaptic vesicles, but are synthetized and released on demand in the postsynaptic terminals in response to elevations of intracellular $\mathrm{Ca} 2+[4]$. These compounds act as retrograde synaptic messengers travelling across synapses, where they bind to presynaptic cannabinoid receptors located in both neurons [5] and glia [6] to modulate neurotransmitter release. CB1R are the most abundant GPCR in the central nervous system (CNS) [7] and are widely distributed in the brain in areas such as the cortex, hippocampal formation, basal ganglia, and cerebellum [8]. In all these structures, CB1R are localized presynaptically on serotonergic, noradrenergic, dopaminergic, GABAergic, and glutamatergic nerve terminals [9-11]. However, there is also data demonstrating a postsynaptic localization for $\mathrm{CB} 1 \mathrm{R}[12,13]$ in cortical dendrites where they can modulate self-inhibition processes [14,15], and in dendrites of a subset of hippocampal pyramidal neurons that upon activation recruit c-Jun-N-terminal kinases and nitric oxide [16]. In addition, CB1R are present intracellularly in mitochondria, at both presynaptic terminals and at 
somatodendritic compartments of glutamatergic and GABAergic hippocampal neurons [17]. Both cannabinoid CB1R and CB2R are mainly coupled to Gi/o resulting in the inhibition of the adenylate cyclase/cAMP cascade and voltage-gated $\mathrm{Ca} 2+$ channels, as well as the stimulation of inwardly rectifying $\mathrm{K}+$ currents, and of mitogen-activated protein kinase (MAPK) activity [18]. Interestingly, a growing amount of evidence shows that CB1R can couple with different subunits of the classic inhibitory Gi/o proteins, but also with $\mathrm{G} \alpha \mathrm{z}, \mathrm{G} \alpha \mathrm{q} / 11$, and $\mathrm{G} \alpha 12 / 13[19,20]$, and that under specific circumstances, CB1R can shift toward activation of Gs and potentiation of neurotransmission $[21,22]$. In addition, activation of $\mathrm{CB} 1 \mathrm{R}$ in astrocytes increases intracellular calcium probably mediated by Gq proteins [23], and in the cardiovascular system, CB1R can bind to $\mathrm{Gs}$ or $\mathrm{Gq} / 11$ to modulate vasoconstriction and hypertension [24]. The ECS is involved in a wide variety of brain processes including brain plasticity, learning and memory, nociception, inflammation, appetite regulation, metabolism, energy balance, sleep-wake cycle, regulation of stress, emotions, reward and addiction [25-27]. Fundamentally, this neuroregulatory system is highly complex and a great amount of research is still being carried out to understand more about the intricate ways in which the ECS functions in normal and pathological states.

The orexin/hypocretin (OX) system is composed of two endogenous ligands: OX-A/ hypocretin-1 and OX-B/ hypocretin-2, and two GPCRs: the OX-1/ hypocretin-1 (OX1R) and the OX-2/ hypocretin-2 (OX2R) receptors. OX-A and OX-B are neuropeptides produced from a common precursor peptide by a cascade of enzymatic reactions $[28,29]$. OX-A is a 33 amino acid peptide activating both OX1R and OX2R with similar potencies, whereas OX-B is a 28 amino acid peptide that is modestly selective for the OX2R [28]. OX-expressing cell bodies are specifically localized in the lateral and perifornical areas of the hypothalamus, but their projections are widely 
distributed throughout the CNS [28-31]. The OX receptors are abundantly expressed in the cerebral cortex, basal ganglia, ventral tegmental area (VTA), nucleus accumbens, hippocampus, hypothalamic and thalamic nuclei, dorsal and medial raphe, locus coeruleus (LC), preoptic area, periaqueductal gray (PAG) and reticular formation [32]. OX1R activation triggers signaling through $\mathrm{Gq} / 11$ proteins resulting in activation of phospholipase $\mathrm{C}$ with subsequent initiation of the phosphatidylinositol cascade. However, in Chinese hamster ovary $(\mathrm{CHO})$ cells expressing OX1R, other types of signaling have been described such as coupling to phospholipase A2 and DAGL, with the subsequent production of 2-AG [33], or Gi-protein coupling with inhibition of AC [34]. In addition, in primary neuronal cell cultures from rat cerebral cortex [35] and in primary cultures of rat astrocytes [36], OX1R stimulate cAMP production. OX2R have also been shown to couple with multiple $\mathrm{G}$ proteins including both $\mathrm{Gq} / 11$ and inhibitory Gi proteins [37]. Stimulation of both receptors activates the MAP kinase pathway leading to ERK1/2 and p38 kinase phosphorylation [38,39]. The OX system is involved in the control of numerous physiological functions and behaviors including attention, alertness, locomotion, regulation of sleep, reward and motivational processes, food intake, energy balance and metabolism [40]. OXs also have antinociceptive effects at spinal and supraspinal levels in several pain models [41], and are involved in stressinduced analgesia [42].

The ECS and OX system have common anatomical distributions in the CNS and thus share physiological functions $[8,32,43]$. OX1R, OX2R and CB1R are widely expressed in the hypothalamus where they regulate energy homeostasis and central neuroendocrine and autonomic functions $[40,44]$. In the mesocorticolimbic system, the septal nuclei and the amygdaloid nuclei, both OX receptors and CB1R co-exist and regulate natural reward and addiction processes [45-47]. Moreover, these receptors are 
located in brain stem areas such as the raphe nuclei, the LC, the reticular formation and the PAG, where they are involved in the regulation of anxiety-like responses, sleep/wake cycle and nociception [48-50].

This review is not set out to be an exhaustive account of the functions of the ECS and OX system, but rather an update of the bidirectional interactions between these systems that have been reported in the last years, specifically in the areas of appetite regulation and energy balance, nociception and reward processes.

\section{Biochemical interactions between orexins and cannabinoids}

A growing body of biochemical and functional evidence suggests that GPCRs, historically considered monomers, form and function as homo- and heterodimers, or even higher-ordered oligomers. These dimers/oligomers often display unique ligand binding, distinct phenotypic trafficking, and specific signaling properties in comparison with their individual monomers [51,52]. Congruent with an overlapping distribution of CB1R and OX1R in certain brain areas, the first evidence of functional cross-talk between these receptors was demonstrated by co-expression of $\mathrm{CB} 1 \mathrm{R}$ and $\mathrm{OX} 1 \mathrm{R}$ in CHO cells [53]. Thus, a major CB1R-dependent enhancement of OX-A's potency to activate the MAPK pathway was shown, and this effect required functional CB1R since the specific $\mathrm{CB} 1 \mathrm{R}$ antagonist rimonabant blocked this response. Moreover, by electron microscopy experiments, the authors concluded that $\mathrm{CB} 1 \mathrm{R}$ and $\mathrm{OX} 1 \mathrm{R}$ were close enough to form hetero-oligomers [53]. The possible existence of CB1R-OX1R heteromerization was further assessed by co-expressing both receptors in HEK293 cells [54]. Treatment with rimonabant resulted in decreased potency of OX-A to activate the MAPK ERK1/2 only in cells co-expressing the two receptors. The OX1R antagonist 
SB-674042 also reduced the potency of a CB1R receptor agonist to phosphorylate ERK1/2 only when the two receptors were co-expressed [54]. Moreover, single cell fluorescence resonance energy transfer (FRET) imaging indicated that both CB1R and OX1R were present as heterodimers/oligomers in intracellular vesicles [54]. More recently, the same group provided further evidence of such heteromerization based on covalent labeling of extracellular domains of CB1R and OX1R with "SNAP" and "CLIP" tags. These are polypeptides which can be labeled covalently with a variety of reagents such as cell-impermeant fluorophores, allowing reliable monitoring of these heteromers at the cell surface [55]. Interestingly, a higher potency of OX-A to regulate the CB1R-OXR1 heteromer compared with the OX1R-OX1R homomer was found in this study, suggesting a functional interplay between these two systems [55]. The formation of CB1R-OX1R heteromeric complexes has been recently demonstrated in embryonic mouse hypothalamic neurons [56]. These heteromers were found to affect intracellular calcium levels, 2-AG biosynthesis and ERK phosphorylation [56]. In addition, by using a bioluminescence energy transfer (BRET) assay, both OX1R and OX2R subtypes were shown to be capable of forming constitutive homo- and heteromeric complexes with one-another and with CB1R [57]. However, although all these data provide unequivocal identification of CB1R-OX1R heteromerization, whether these complexes are functional under physiological conditions, and whether they are dynamically regulated remains to be elucidated [58]. The development of bivalent ligands, which preferentially interact with the receptor heterodimers, will represent a possible approach of determining their physiological significance [59].

Apart from heteromerization, some studies suggest that the most important part of the interaction between $\mathrm{CB} 1 \mathrm{R}$ and $\mathrm{OX} 1 \mathrm{R}$ results from 2-AG production in response to $\mathrm{OX}$ stimulation [60]. Release of 2-AG following the administration of OX-A has been 
demonstrated in CHO cells [33]. In these cells, the activation of PLC was shown to be responsible for DAG production, which in turn is used by DAGL as a substrate for 2AG formation [33]. Therefore, it is possible that the activation of CB1R by 2-AG could contribute to increase the potency of $\mathrm{OX}$ signaling observed in $\mathrm{CHO}$ cells. Moreover, as it will be described later in this review, this $\mathrm{OX}$-induced 2-AG release has been demonstrated to be of great relevance in several studies. Thus, 2-AG modulates the effects of OXs on nociception, addiction and food intake.

\section{Involvement of endocannabinoids in the effects of orexins on food intake and} energy balance

The OX system is a key modulator of both food intake and energy expenditure. Under physiological conditions, hormonal control of food intake is mainly mediated by the action of leptin and ghrelin in the hypothalamus, where they exert opposing effects on the activity of anorexigenc pro-opiomelanocortin (POMC)/cocaine-amphetaminerelated transcripts (CART), and orexigenic agouti-related peptide (AgRP)/neuropeptide Y (NPY) neurons in the arcuate nucleus. Leptin, produced by adipocytes, indirectly controls the activity of OX neurons via long form leptin receptors (LepRb) in neurotensin-expressing cells in the lateral hypothalamus (LH) [61,62], and through the action of neuropeptides released from the POMC or AgRP/NPY neurons [63,64]. On the other hand, ghrelin released during fasting directly activates OX neurons by binding to ghrelin receptors (GHSR) located in these neurons [65-67]. Correspondingly, OX stimulates orexigenic NPY-containing neurons and decreases the activity of anorexigenic POMC-containing neurons, via OX1R [68,69]. Thus, the control of feeding by OX involves local bidirectional interactions in the hypothalamus between OX neurons and NPY and POMC cells [70-73], their modulation by peripheral 
hormones, and their output connections to limbic, locomotor, autonomic and neuroendocrine systems $[28,29,74]$.

Furthermore, the control of the pathways involved in homeostatic food intake is preponderantly modulated by the ECS. Thus, the levels of 2-AG increase in the hypothalamus in normal animals during fasting, decrease during refeeding, and return to normal when rats are satiated [75], while in rodent models of obesity, elevated levels of endocannabinoids within hypothalamic nuclei have been observed [76,77]. In addition, a wide distribution of $\mathrm{CB} 1 \mathrm{R}$ has been demonstrated in the hypothalamus, with a presynaptic localization on GABAergic terminals innervating NPY/AgRP and melaninconcentrating hormone $(\mathrm{MCH})$ neurons and on glutamatergic projections to $\mathrm{OX}$ neurons [78], and positioned post-synaptically on POMC/CART [69] and corticotrophinreleasing hormone [25] neurons. Under physiological conditions, the orexigenic action of cannabinoids has been attributed mainly to their excitatory effect on $\mathrm{MCH}$ cells mediated by inhibition of inhibitory GABAergic input to these neurons. In contrast, cannabinoids reduce the activity of $\mathrm{OX}$ cells due to the presynaptic attenuation of glutamate release, leading to a decrease in arousal [78]. In addition, it has been shown that the peripheral administration of sub-threshold doses of the CB1R antagonist rimonabant blocks the orexigenic effect of OX-A administered by intracerebroventricular route [79]. The ECS may influence food intake by regulating the expression and/or action of OXs. Thus, intracerebroventricular injection of the CB1R inverse agonist AM251 produced a significant decrease in the number of neurons expressing OX-A in the hypothalamus [80].

In conditions where hormone levels are dysregulated, such as in obesity, OX neurons may contribute to hyperphagia and obesity [81]. Indeed, in leptin-knockout (ob/ob), and in diet-induced obese mice the balance between GABA/Glutamatergic innervation to 
OX cells is shifted to predominantly inhibitory CB1R-expressing inputs. An overexpression of the biosynthetic enzyme for the endocannabinoid 2-AG, DAGL, was also observed in these animals. These changes were reversed by leptin administration. Notably, these alterations lead to a retrograde inhibition of GABAergic terminals by 2AG, increased neuronal activity of OX cells, and enhanced signaling activity in projection areas mediating reward, motivation and food intake, such as the VTA, nucleus accumbens and arcuate nucleus [81]. Subsequent electrophysiological studies in slices from the LH of ob/ob mice confirmed that the upregulation of 2-AG by OX neurons leads mainly to a depression of inhibition, and consequently the excitatory drive on OX neurons becomes functionally predominant [82]. More recently, a role for the interaction between $\mathrm{OX}-\mathrm{A}$ release in the arcuate nucleus and $\mathrm{CB} 1 \mathrm{R}$ located in POMC neurons has been put forward in promoting hyperphagia [69]. Thus, the activation of OX1R by OX-A induces the synthesis of 2-AG, which binds to postsynaptic CB1R in POMC cells leading to a decrease in POMC and $\alpha$-melanocytestimulating hormone ( $\alpha$-MSH) synthesis in the paraventricular nucleus of the hypothalamus, and to hyperphagia (Figure 1). During obesity, characterized by leptin signaling deficiency, this system is hyperactivated and high levels of OX-A and 2-AG correlate with decreased $\alpha$-MSH levels and increased body mass index [69].

Interestingly, OX neurons have also been shown to protect the body from obesity by promoting energy expenditure [83]. Thus, the overexpression of OXs induces resistance to high fat diet-induced obesity and insulin insensitivity by promoting energy expenditure and reducing food consumption. This action of OX cells is partly mediated through OX2R and an increase in leptin sensitivity [84]. More recently, using in vivo calcium imaging it has been demonstrated that $\mathrm{OX}$ neurons are activated by hunger signals, but are rapidly inactivated by eating irrespective of the nature of the food, 
reducing food foraging and promoting storage of energy $[85,86]$. On the other hand, the complete selective inactivation of the OX system in the brain can promote overeating and increases body weight in free-feeding mice, a condition that is reversed by dieting [85]. These studies indicate that the OX system is more involved in food seeking than in food consumption, and put forward the interesting notion that in pathological conditions where the activity of OX neurons is dysregulated, adjustments in food intake could play a normalizing role [85].

The ECS also modulates body weight and fat mass, probably through peripheral lipogenesis [87]. In addition, chronic blockade of CB1R improves peripheral metabolic parameters. Notably, an interaction between the OX system and the ECS on feeding behavior and on the activity of glucose sensitive neurons in the arcuate nucleus has been recently suggested. Thus, the local administration of the CB1R antagonist AM251 into the arcuate nucleus modulates food intake induced by OX-A, and blunts its effects on glucose responsive neurons in this structure [88]. However, it is still not known whether the OX system and the ECS interact in periphery and in the brain to modulate energy balance.

\section{Involvement of endocannabinoids in the effects of orexins on nociception}

OX neurons project to several regions of the CNS involved in the regulation of pain, including the ventrolateral periaqueductal gray (vlPAG) and spinal dorsal horn, where OX receptors are densely distributed [30,32]. The descending antinociceptive pathway controls pain perception at the spinal level by the activation of PAG neurons leading to the excitation of cells in the rostroventral medulla, that send inhibitory projections to the dorsal horn of the spinal cord via the dorsolateral funiculus [89]. The antinociceptive effects of OXs have been widely demonstrated (see [41] for review), and one 
mechanism that has been proposed to explain this role is the interaction with the ECS at the level of the PAG. Hence, Ho et al. [90] have demonstrated that activation of OX1R by $\mathrm{OX}-\mathrm{A}$ in PAG slices increases the synthesis of $2-\mathrm{AG}$ via the phospholipase $\mathrm{C}$ DAGL $\alpha$ route, and inhibits GABAergic tone leading to an increase in PAG neuronal activity (Figure 1). This mechanism of action has also been postulated to contribute to stress-induced analgesia [91]. In addition, recent studies show that although both OX-A and an OX2R selective agonist injected in the vlPAG induce antinociception, only OX1R-mediated antinociception is blocked by the CB1R receptor antagonist AM 251 [42]. Moreover, the antinociceptive effect of intra-LH administration of carbachol is mediated through the activation of OX1R and OX2R in the vlPAG $[92,93]$. CB1R activation in this brain area also contributes to the modulation of carbachol-induced antinociception [92,93]. In addition, the OX system and the ECS interact at other brain areas involved in nociception, such as the LC since local administration of OX-A in this area induces analgesia through activation of OX1R and CB1R [94]. Finally, since eating disorders/obesity are often associated to altered pain perception [95], the relationship between the OX system and the ECS has been investigated in this case. Obese ob/ob mice exhibiting total leptin deficiency show hypoalgesic behavior associated with an increase in OX-A and 2-AG levels in the vlPAG, leading to the disinhibition of the vlPAG neurons and activation of the descending antinociceptive pathway [95]. Furthermore, these authors found that high fat diet-induced obese mice showing leptin signaling deficiency only in the arcuate nucleus, also present high levels of OX-A and 2-AG in the vlPAG, but analgesia is only unmasked following systemic leptin receptor antagonism. Therefore, they concluded that the activation of the descending antinociceptive pathway mediated by the interaction between the OX and ECS partly 
underlies the increased pain thresholds in conditions associated with impaired leptin signaling [95].

\section{Involvement of endocannabinoids in the modulation of the brain reward system}

\section{by orexins}

The OX system regulates the mesocorticolimbic dopaminergic pathway, which is the circuit responsible for the pleasure feelings associated with natural and drug rewards. Numerous studies have demonstrated a role for the OX system in the addictive properties of drugs of abuse [47,96], consistent with the existence of reciprocal connections between OX-rich nuclei and brain areas involved in reward processing [30], including the VTA and the nucleus accumbens. OXs seem to regulate reward seeking by modulating VTA dopaminergic transmission. In agreement, intra-VTA injection of OX-A increased extracellular dopamine levels in both the prefrontal cortex and the nucleus accumbens [97]. OXs influence VTA dopamine cell firing not only via direct depolarization [98], but also by interacting with glutamate and GABA transmission. Activation of GABAergic neurons in the VTA constitutes an inhibitory input on dopaminergic neurons, while increase of glutamate transmission is an excitatory influence on VTA dopaminergic activity. In brain slices, OXs were shown to increase dopaminergic activity in the VTA via long-term potentiation of glutamatergic transmission [99], and also by directly increasing the firing of GABAergic neurons [98]. Although activation of GABAergic cells is predicted to decrease VTA dopaminergic activity, OXs could facilitate a switch in the balance between excitatory and inhibitory synaptic inputs to VTA dopaminergic neurons in some conditions, such as the exposure to drugs of abuse. Indeed, the ability of $\mathrm{OX}$ to increase glutamate transmission in 
parallel with a decrease in GABA transmission in the VTA has been recently described in brain slices of animals treated with morphine by using electrophysiology [100]. On the other hand, it is well established that endocannabinoids and CB1R participate in the rewarding properties of natural rewards, and also in those induced by different drugs of abuse $[45,101]$. Acting as retrograde messengers, endocannabinoids produce inhibition of neurotransmitter release in the VTA. The activation of CB1R located on axon terminals of GABAergic neurons in the VTA inhibits GABA transmission, thus removing this inhibitory input on dopaminergic neurons [102]. Glutamatergic transmission in the VTA, arising mainly from neurons of the prefrontal cortex, is similarly inhibited by CB1R activation [103]. The final effect of endocannabinoids on the modulation of VTA dopamine neurons, which depends on the balance between excitatory and inhibitory inputs, is predominantly excitatory [45].

A recent study has revealed an interesting interaction between OXs and endocannabinoids within the VTA in the regulation of cocaine relapse induced by stress [104]. In a sequence of elegant experiments, these authors demonstrated that acute restraint stress activates OX neurons in the LH, increases OX-A levels in the VTA, and reinstates extinguished conditioned place preference induced by cocaine. Notably, the activation of postsynaptic OX1R on VTA dopaminergic neurons by OXs leads to the production of 2-AG through the PLC and DAGL enzymatic cascade, which then retrogradely inhibits GABA release through CB1R, followed by the disinhibition of VTA dopaminergic neurons [104]. Moreover, stress-induced reinstatement of cocaine place preference was prevented by either systemic or intra-VTA injection of an OX1R or CB1R antagonist, and by a DAGL inhibitor [104]. This study provides a novel mechanism for stress-induced cocaine relapse based on this OX1R-PLC-DAGL-2-AG cascade in charge of the final disinhibition of VTA dopaminergic neurons (Figure 1). In 
agreement with this mechanism, a previous behavioral study showed that intra-VTA injection of $\mathrm{CB} 1 \mathrm{R}$ receptor or OX1R antagonists produced comparable and nonadditive reductions in the conditioned place preference induced by chemical stimulation of the LH with the cholinergic agonist carbachol [105]. This result suggests that CB1R and OX1R in the VTA regulate this behavioral response by a common mechanism, rather than activating two parallel pathways. In addition, an interaction between CB1R and both $\mathrm{OX} 1 \mathrm{R}$ and $\mathrm{OX} 2 \mathrm{R}$ in the nucleus accumbens has also been shown to be involved in the conditioned place preference induced by LH stimulation $[106,107]$. Recently, it has been described that OX2R and CB1R located in the VTA play a role in the rewarding properties of nicotine as revealed by using a conditioned place preference paradigm [108]. Future investigation at molecular, cellular and behavioral levels will be required to better understand the exact mechanisms and potential therapeutic implications of the interaction between these systems in the regulation of the reward circuit. The formation of CB1R-OX1R heteromers with specific signaling properties could be important for the interaction of these systems in the regulation of reward, as has been previously described for CB1R and dopamine D2 receptors [21].

\section{Involvement of orexins in the pharmacological effects of cannabinoids}

As described in the previous sections of this review, the contribution of the ECS in several physiological functions of $\mathrm{OX}$ has been clearly established. However, so far few studies have evaluated whether the opposite is also occurring, that is, does the OX system participate in the pharmacological effects of cannabinoids? A relevant aspect of OX-cannabinoid interplay is observed in the addictive properties of cannabinoids. Cannabis is the most frequently used illicit drug worldwide, and the number of people 
seeking treatment for cannabis use disorder has dramatically increased in the last decades [109]. Therefore, the identification of new therapeutic targets to improve treatment outcomes for cannabis dependence is imperative considering that currently there are no effective pharmacotherapeutic approaches for this disorder [110].

The first evidence supporting the modulation of OXs on cannabis dependence was based on modifications in the expression of OX-A in peripheral blood cells in cannabisdependent smokers when compared to nicotine-dependent smokers and non-smokers [111]. However, peripheral OX mRNA levels do not necessarily reflect the situation in the CNS; hence these differences are probably related to the peripheral actions of $\Delta^{9}$ tetrahydrocannabinol (THC), and not to its central effects involved in the development of dependence. Nevertheless, subsequent behavioral studies have demonstrated that the OX system modulates cannabinoid reward. Thus, the intravenous self-administration of the synthetic cannabinoid WIN55,212-2 was reduced by both genetic deletion and pharmacological blockade of OX1R [112]. In contrast, OX2R were not involved in this response. Also, the increase in dopamine extracellular levels in the nucleus accumbens induced by THC was blocked in mice lacking the OX1R, suggesting that cannabinoids require orexinergic transmission to modulate the dopaminergic mesolimbic pathway. Moreover, contingent WIN55,212-2 self-administration, but not passive exposure to this cannabinoid, increased the activation of OX neurons in the LH [112], indicating that the recruitment of OX cells within this structure is mainly due to operant seeking for the reinforcing effects of this drug, and not to its pharmacological actions [112]. As a whole, these data show that OX1R antagonists could represent an interesting pharmacological tool for cannabis dependence in humans.

In a more general sense, a recent study evaluated the involvement of the OX system in several acute pharmacological effects of THC. The hypothermia, supraspinal 
antinociception and anxiolytic-like effects induced by THC were modulated by OX through OX2R signaling [113]. In contrast, OXs were not shown to be involved in the hypolocomotion, spinal antinociception, amnesic- or anxiogenic-like effects produced by this cannabinoid. Interestingly, OX1R did not participate in any acute pharmacological effects of THC [113]. Therefore, the blockade of OX1R would specifically abolish the reinforcing properties of cannabinoids without affecting other pharmacological responses of these compounds [112,113] (Figure 2). This is important since one of the major challenges in cannabinoid research consists in identifying possible mechanisms to dissociate the therapeutic action of cannabis from its detrimental consequences, among which cannabis addiction represents a pivotal concern.

\section{Concluding remarks}

Anatomical, biochemical and behavioral studies support the existence of bidirectional interactions between the ECS and the OX system. There is an increasing amount of data indicating that endocannabinoids exert a crucial modulation of the effects of OXs on food seeking and antinociception through the release of 2-AG in hypothalamic and brain stem areas. Moreover, new data is pointing towards a relevant role of OXs on stress-induced cocaine relapse also via a 2-AG-mediated mechanism in brain reward structures. This intriguing evidence emphasizes the prominent role of the endocannabinoid-mediated retrograde inhibition of GABAergic neurons in several major physiological brain functions: motivation for food and drug reward, as well as, a pain perception. The involvement of OX1R in the rewarding properties of cannabinoids, but not in other pharmacological effects, is of special interest since OX1R antagonists could be potentially useful to treat cannabis dependence without affecting other 
beneficial properties of these compounds. Although the mechanisms underlying this interaction are poorly understood, the existence of CB1R-OX1R heteromers with specific functional signaling properties could be the basis for some of these effects. The development of new tools to further probe this functional interaction may lead to novel therapeutic approaches to neurological disorders mediated by these receptors. This field, where OXs meet cannabinoids will certainly expand with time as research develops on their molecular and behavioral interactions, providing deeper insight into its relevance in physiological and pathological conditions, and a better understanding of their potential therapeutic implications. 


\section{Acknowledgements}

This work was supported by Instituto de Salud Carlos III (PI14/00210), the Fundació la Marató de TV3 (231/C/2014) to PR, "Plan Nacional sobre Drogas" (\#2014I019) and

"Ministerio de Economía y Competitividad" (SAF2017-85299-R) to FB, and the Catalunya Government AGAUR (2017SGR210). We would like to thank Carla Ramón Duaso for her help with reference editing.

\section{Conflict of interest}

The authors declare no competing interests. 


\section{References}

[1] P.M. Zygmunt, J. Petersson, D.A. Andersson, H. Chuang, M. Sørgård, V. Di Marzo, D. Julius, E.D. Högestätt, Vanilloid receptors on sensory nerves mediate the vasodilator action of anandamide., Nature. 400 (1999) 452-7. doi:10.1038/22761.

[2] G.R. Ross, A. Lichtman, W.L. Dewey, H.I. Akbarali, Evidence for the putative cannabinoid receptor (GPR55)-mediated inhibitory effects on intestinal contractility in mice., Pharmacology. 90 (2012) 55-65. doi:10.1159/000339076.

[3] L. De Petrocellis, M.G. Cascio, V. Di Marzo, The endocannabinoid system: a general view and latest additions., Br. J. Pharmacol. 141 (2004) 765-74. doi:10.1038/sj.bjp.0705666.

[4] R.G. Pertwee, A.C. Howlett, M.E. Abood, S.P.H. Alexander, V. Di Marzo, M.R. Elphick, P.J. Greasley, H.S. Hansen, G. Kunos, K. Mackie, R. Mechoulam, R.A. Ross, International Union of Basic and Clinical Pharmacology. LXXIX. Cannabinoid receptors and their ligands: beyond $\mathrm{CB}_{1}$ and $\mathrm{CB}_{2}$., Pharmacol. Rev. 62 (2010) 588-631. doi:10.1124/pr.110.003004.

[5] B.S. Basavarajappa, Neuropharmacology of the endocannabinoid signaling system-molecular mechanisms, biological actions and synaptic plasticity., Curr. Neuropharmacol. 5 (2007) 81-97. doi:10.2174/157015907780866910.

[6] A. Covelo, A. Araque, Lateral regulation of synaptic transmission by astrocytes., Neuroscience. 323 (2016) 62-6. doi:10.1016/j.neuroscience.2015.02.036.

[7] M. Herkenham, A.B. Lynn, M.D. Little, M.R. Johnson, L.S. Melvin, B.R. de 
Costa, K.C. Rice, Cannabinoid receptor localization in brain., Proc. Natl. Acad. Sci. U. S. A. 87 (1990) 1932-6.

[8] M. Herkenham, a B. Lynn, M.R. Johnson, L.S. Melvin, B.R. de Costa, K.C. Rice, Characterization and localization of cannabinoid receptors in rat brain: a quantitative in vitro autoradiographic study, J. Neurosci. 11 (1991) 563-583. doi:10.1523/JNEUROSCI.11-02-00563.1991.

[9] H. Hermann, G. Marsicano, B. Lutz, Coexpression of the cannabinoid receptor type 1 with dopamine and serotonin receptors in distinct neuronal subpopulations of the adult mouse forebrain., Neuroscience. 109 (2002) 451-60.

[10] V.C. Oropeza, K. Mackie, E.J. Van Bockstaele, Cannabinoid receptors are localized to noradrenergic axon terminals in the rat frontal cortex., Brain Res. 1127 (2007) 36-44. doi:10.1016/j.brainres.2006.09.110.

[11] S.C. Azad, J. Kurz, G. Marsicano, B. Lutz, W. Zieglgänsberger, G. Rammes, Activation of CB1 specifically located on GABAergic interneurons inhibits LTD in the lateral amygdala., Learn. Mem. 15 (2008) 143-52. doi:10.1101/1m.741908.

[12] P. Schweitzer, Cannabinoids decrease the $\mathrm{K}(+)$ M-current in hippocampal CA1 neurons., J. Neurosci. 20 (2000) 51-58.

[13] S. Zhuang, R.E. Hampson, S.A. Deadwyler, Behaviorally relevant endocannabinoid action in hippocampus: dependence on temporal summation of multiple inputs., Behav. Pharmacol. 16 (2005) 463-71. doi:10.1097/00008877200509000-00020.

[14] A. Bacci, J.R. Huguenard, D.A. Prince, Long-lasting self-inhibition of neocortical interneurons mediated by endocannabinoids., Nature. 431 (2004) 
312-6. doi:10.1038/nature02913.

[15] S. Marinelli, S. Pacioni, A. Cannich, G. Marsicano, A. Bacci, Self-modulation of neocortical pyramidal neurons by endocannabinoids., Nat. Neurosci. 12 (2009) 1488-90. doi:10.1038/nn.2430.

[16] M. Maroso, G.G. Szabo, H.K. Kim, A. Alexander, A.D. Bui, S.-H. Lee, B. Lutz, I. Soltesz, Cannabinoid control of learning and memory through HCN channels., Neuron. 89 (2016) 1059-73. doi:10.1016/j.neuron.2016.01.023.

[17] G. Bénard, F. Massa, N. Puente, J. Lourenço, L. Bellocchio, E. Soria-Gómez, I. Matias, A. Delamarre, M. Metna-Laurent, A. Cannich, E. Hebert-Chatelain, C. Mulle, S. Ortega-Gutiérrez, M. Martín-Fontecha, M. Klugmann, S. Guggenhuber, B. Lutz, J. Gertsch, F. Chaouloff, M.L. López-Rodríguez, P. Grandes, R. Rossignol, G. Marsicano, Mitochondrial $\mathrm{CB}_{1}$ receptors regulate neuronal energy metabolism., Nat. Neurosci. 15 (2012) 558-64. doi:10.1038/nn.3053.

[18] F.A. Iannotti, V. Di Marzo, S. Petrosino, Endocannabinoids and endocannabinoid-related mediators: Targets, metabolism and role in neurological disorders., Prog. Lipid Res. 62 (2016) 107-28. doi:10.1016/j.plipres.2016.02.002.

[19] P.L. Prather, N. a Martin, C.S. Breivogel, S.R. Childers, Activation of cannabinoid receptors in rat brain by WIN 55212-2 produces coupling to multiple G protein alpha-subunits with different potencies., Mol. Pharmacol. 57 (2000) 1000-1010.

[20] R. Diez-Alarcia, I. Ibarra-Lecue, Á.P. Lopez-Cardona, J. Meana, A. GutierrezAdán, L.F. Callado, E. Agirregoitia, L. Urigüen, Biased agonism of three different cannabinoid receptor agonists in mouse brain cortex., Front. Pharmacol. 7 (2016) 415. doi:10.3389/fphar.2016.00415. 
[21] C.S. Kearn, K. Blake-Palmer, E. Daniel, K. Mackie, M. Glass, Concurrent stimulation of cannabinoid CB1 and dopamine D2 receptors enhances heterodimer formation: a mechanism for receptor cross-talk?, Mol. Pharmacol. 67 (2005) 1697-704. doi:10.1124/mol.104.006882.

[22] R.N. Caballero-Florán, I. Conde-Rojas, A. Oviedo Chávez, H. Cortes-Calleja, L.F. Lopez-Santiago, L.L. Isom, J. Aceves, D. Erlij, B. Florán, Cannabinoidinduced depression of synaptic transmission is switched to stimulation when dopaminergic tone is increased in the globus pallidus of the rodent., Neuropharmacology. 110 (2016) 407-418. doi:10.1016/j.neuropharm.2016.08.002.

[23] M. Navarrete, A. Araque, Endocannabinoids mediate neuron-astrocyte communication., Neuron. 57 (2008) 883-93. doi:10.1016/j.neuron.2008.01.029.

[24] M. Szekeres, G.L. Nádasy, G. Turu, E. Soltész-Katona, Z. Benyó, S. Offermanns, É. Ruisanchez, E. Szabó, Z. Takáts, S. Bátkai, Z.E. Tóth, L. Hunyady, Endocannabinoid-mediated modulation of $\mathrm{Gq} / 11$ protein-coupled receptor signaling-induced vasoconstriction and hypertension., Mol. Cell. Endocrinol. 403 (2015) 46-56. doi:10.1016/j.mce.2015.01.012.

[25] Á. Flores, R. Maldonado, F. Berrendero, Cannabinoid-hypocretin cross-talk in the central nervous system: What we know so far, Front. Neurosci. (2013). doi:10.3389/fnins.2013.00256.

[26] A. Busquets-Garcia, T. Desprez, M. Metna-Laurent, L. Bellocchio, G. Marsicano, E. Soria-Gomez, Dissecting the cannabinergic control of behavior: The where matters, BioEssays. 37 (2015) 1215-1225. doi:10.1002/bies.201500046. 
[27] M.S. Crowe, S.R. Nass, K.M. Gabella, S.G. Kinsey, The endocannabinoid system modulates stress, emotionality, and inflammation, Brain. Behav. Immun. 42 (2014) 1-5. doi:10.1016/j.bbi.2014.06.007.

[28] T. Sakurai, A. Amemiya, M. Ishii, I. Matsuzaki, R.M. Chemelli, H. Tanaka, S.C. Williams, J.A. Richardson, G.P. Kozlowski, S. Wilson, J.R.. Arch, R.E. Buckingham, A.C. Haynes, S.A. Carr, R.S. Annan, D.E. McNulty, W.S. Liu, J.A. Terrett, N.A. Elshourbagy, D.J. Bergsma, M. Yanagisawa, Orexins and orexin receptors: a family of hypothalamic neuropeptides and $\mathrm{G}$ protein-coupled receptors that regulate feeding behavior., Cell. 92 (1998) 573-85. doi:10.1016/S0092-8674(00)80949-6.

[29] L. de Lecea, T.S. Kilduff, C. Peyron, X.-B. Gao, P.E. Foye, P.E. Danielson, C. Fukuhara, E.L. Battenberg, V.T. Gautvik, F.S. Bartlett, W.N. Frankel, A.N. van den Pol, F.E. Bloom, K.M. Gautvik, J.G. Sutcliffe, The hypocretins: hypothalamus-specific peptides with neuroexcitatory activity., Proc. Natl. Acad. Sci. U. S. A. 95 (1998) 322-7.

[30] C. Peyron, D.K. Tighe, A.N. van den Pol, L. de Lecea, H.C. Heller, J.G. Sutcliffe, T.S. Kilduff, Neurons containing hypocretin (orexin) project to multiple neuronal systems., J. Neurosci. 18 (1998) 9996-10015.

[31] A.N. van den Pol, X.B. Gao, K. Obrietan, T.S. Kilduff, A.B. Belousov, Presynaptic and postsynaptic actions and modulation of neuroendocrine neurons by a new hypothalamic peptide, hypocretin/orexin., J. Neurosci. 18 (1998) 796271.

[32] J.N. Marcus, C.J. Aschkenasi, C.E. Lee, R.M. Chemelli, C.B. Saper, M. Yanagisawa, J.K. Elmquist, Differential expression of orexin receptors 1 and 2 in 
the rat brain., J. Comp. Neurol. 435 (2001) 6-25. doi:10.1002/cne.1190.

[33] P.M. Turunen, M.H. Jäntti, J.P. Kukkonen, OX1 orexin/hypocretin receptor signaling through arachidonic acid and endocannabinoid release., Mol. Pharmacol. 82 (2012) 156-67. doi:10.1124/mol.112.078063.

[34] T. Holmqvist, L. Johansson, M. Ostman, S. Ammoun, K.E.O. Akerman, J.P. Kukkonen, OX1 orexin receptors couple to adenylyl cyclase regulation via multiple mechanisms., J. Biol. Chem. 280 (2005) 6570-9. doi:10.1074/jbc.M407397200.

[35] A. Urbańska, P. Sokołowska, A. Woldan-Tambor, K. Biegańska, B. Brix, O. Jöhren, M. Namiecińska, J.B. Zawilska, Orexins/hypocretins acting at Gi proteincoupled OX 2 receptors inhibit cyclic AMP synthesis in the primary neuronal cultures., J. Mol. Neurosci. 46 (2012) 10-7. doi:10.1007/s12031-011-9526-2.

[36] A. Woldan-Tambor, K. Biegańska, A. Wiktorowska-Owczarek, J.B. Zawilska, Activation of orexin/hypocretin type 1 receptors stimulates cAMP synthesis in primary cultures of rat astrocytes., Pharmacol. Rep. 63 (2011) 717-23. doi:10.1016/S1734-1140(11)70583-7.

[37] Y. Zhu, Y. Miwa, A. Yamanaka, T. Yada, M. Shibahara, Y. Abe, T. Sakurai, K. Goto, Orexin receptor type-1 couples exclusively to pertussis toxin-insensitive Gproteins, while orexin receptor type- 2 couples to both pertussis toxin-sensitive and -insensitive G-proteins., J. Pharmacol. Sci. 92 (2003) 259-66.

[38] S. Ammoun, D. Lindholm, H. Wootz, K.E.O. Akerman, J.P. Kukkonen, Gprotein-coupled OX1 orexin/hcrtr-1 hypocretin receptors induce caspasedependent and -independent cell death through p38 mitogen-/stress-activated protein kinase., J. Biol. Chem. 281 (2006) 834-42. doi:10.1074/jbc.M508603200. 
[39] J. Tang, J. Chen, M. Ramanjaneya, A. Punn, A.C. Conner, H.S. Randeva, The signalling profile of recombinant human orexin-2 receptor., Cell. Signal. 20 (2008) 1651-61. doi:10.1016/j.cellsig.2008.05.010.

[40] N. Tsujino, T. Sakurai, Orexin/hypocretin: a neuropeptide at the interface of sleep, energy homeostasis, and reward system., Pharmacol. Rev. 61 (2009) 16276. doi:10.1124/pr.109.001321.

[41] L.-C. Chiou, H.-J. Lee, Y.-C. Ho, S.-P. Chen, Y.-Y. Liao, C.-H. Ma, P.-C. Fan, J.-L. Fuh, S.-J. Wang, Orexins/hypocretins: pain regulation and cellular actions., Curr. Pharm. Des. 16 (2010) 3089-100. doi:10.2174/138161210793292483.

[42] H.J. Lee, L.Y. Chang, Y.C. Ho, S.F. Teng, L.L. Hwang, K. Mackie, L.C. Chiou, Stress induces analgesia via orexin 1 receptor-initiated endocannabinoid/CB1 signaling in the mouse periaqueductal gray, Neuropharmacology. 105 (2016) 577-586. doi:10.1016/j.neuropharm.2016.02.018.

[43] G.J. Hervieu, J.E. Cluderay, D.C. Harrison, J.C. Roberts, R.A. Leslie, Gene expression and protein distribution of the orexin-1 receptor in the rat brain and spinal cord., Neuroscience. 103 (2001) 777-97.

[44] G. Wittmann, L. Deli, I. Kalló, E. Hrabovszky, M. Watanabe, Z. Liposits, C. Fekete, Distribution of type 1 cannabinoid receptor (CB1)-immunoreactive axons in the mouse hypothalamus., J. Comp. Neurol. 503 (2007) 270-9. doi:10.1002/cne.21383.

[45] R. Maldonado, O. Valverde, F. Berrendero, Involvement of the endocannabinoid system in drug addiction., Trends Neurosci. 29 (2006) 225-32. doi:10.1016/j.tins.2006.01.008. 
[46] G. Aston-Jones, R.J. Smith, G.C. Sartor, D.E. Moorman, L. Massi, P. TahsiliFahadan, K.A. Richardson, Lateral hypothalamic orexin/hypocretin neurons: A role in reward-seeking and addiction., Brain Res. 1314 (2010) 74-90. doi:10.1016/j.brainres.2009.09.106.

[47] A. Plaza-Zabala, R. Maldonado, F. Berrendero, The hypocretin/orexin system: implications for drug reward and relapse., Mol. Neurobiol. 45 (2012) 424-39. doi:10.1007/s12035-012-8255-z.

[48] K.S. Eriksson, O.A. Sergeeva, H.L. Haas, O. Selbach, Orexins/hypocretins and aminergic systems., Acta Physiol. (Oxf). 198 (2010) 263-75. doi:10.1111/j.17481716.2009.02015.x

[49] M. Häring, V. Enk, A. Aparisi Rey, S. Loch, I. Ruiz de Azua, T. Weber, D. Bartsch, K. Monory, B. Lutz, Cannabinoid type-1 receptor signaling in central serotonergic neurons regulates anxiety-like behavior and sociability., Front. Behav. Neurosci. 9 (2015) 235. doi:10.3389/fnbeh.2015.00235.

[50] A.R. Wilson-Poe, M.M. Morgan, S.A. Aicher, D.M. Hegarty, Distribution of CB1 cannabinoid receptors and their relationship with mu-opioid receptors in the rat periaqueductal gray., Neuroscience. 213 (2012) 191-200. doi:10.1016/j.neuroscience.2012.03.038.

[51] S.R. George, B.F. O’Dowd, S.P. Lee, G-protein-coupled receptor oligomerization and its potential for drug discovery, Nat. Rev. Discov. 1 (2002) 808-820. doi:10.1038/nrd913.

[52] G. Milligan, G protein-coupled receptor hetero-dimerization: Contribution to pharmacology and function, Br. J. Pharmacol. 158 (2009) 5-14. doi:10.1111/j.1476-5381.2009.00169.x. 
[53] S. Hilairet, M. Bouaboula, D. Carrière, G. Le Fur, P. Casellas, Hypersensitization of the orexin 1 receptor by the CB1 receptor: Evidence for cross-talk blocked by the specific CB1 antagonist, SR141716, J. Biol. Chem. 278 (2003) 23731-23737. doi:10.1074/jbc.M212369200.

[54] J. Ellis, J.D. Pediani, M. Canals, S. Milasta, G. Milligan, Orexin-1 receptorcannabinoid CB1 receptor heterodimerization results in both ligand-dependent and -independent coordinated alterations of receptor localization and function., J. Biol. Chem. 281 (2006) 38812-24. doi:10.1074/jbc.M602494200.

[55] R.J. Ward, J.D. Pediani, G. Milligan, Heteromultimerization of cannabinoid $\mathrm{CB}(1)$ receptor and orexin $\mathrm{OX}(1)$ receptor generates a unique complex in which both protomers are regulated by orexin A., J. Biol. Chem. 286 (2011) 37414-28. doi:10.1074/jbc.M111.287649.

[56] R. Imperatore, L. Palomba, G. Morello, A. Di Spiezio, F. Piscitelli, V. Di Marzo, L. Cristino, Formation of OX-1R/CB1R heteromeric complexes in embryonic mouse hypothalamic cells: Effect on intracellular calcium, 2-arachidonoylglycerol biosynthesis and ERK phosphorylation, Pharmacol. Res. 111 (2016) 600-609. doi:10.1016/j.phrs.2016.07.009.

[57] M.H. Jäntti, I. Mandrika, J.P. Kukkonen, Human orexin/hypocretin receptors form constitutive homo- and heteromeric complexes with each other and with human CB1 cannabinoid receptors., Biochem. Biophys. Res. Commun. 445 (2014) 486-90. doi:10.1016/j.bbrc.2014.02.026.

[58] M.D. Thompson, T. Sakurai, I. Rainero, M.C. Maj, J.P. Kukkonen, Orexin receptor multimerization versus functional interactions: Neuropharmacological implications for opioid and cannabinoid signalling and pharmacogenetics., 
Pharmaceuticals (Basel). 10 (2017) 79. doi:10.3390/ph10040079.

[59] D.A. Perrey, B.P. Gilmour, B.F. Thomas, Y. Zhang, Toward the development of bivalent ligand probes of cannabinoid $\mathrm{CB} 1$ and orexin $\mathrm{OX} 1$ receptor heterodimers., ACS Med. Chem. Lett. 5 (2014) 634-8. doi:10.1021/ml4004759.

[60] M.H. Jantti, J. Putula, P.M. Turunen, J. Nasman, S. Reijonen, C. Lindqvist, J.P. Kukkonen, Autocrine endocannabinoid signaling through CB1 receptors potentiates OX1 orexin receptor signaling, Mol. Pharmacol. 83 (2013) 621-632. doi:10.1124/mol.112.080523.

[61] P.B. Goforth, G.M. Leinninger, C.M. Patterson, L.S. Satin, M.G. Myers, Leptin acts via lateral hypothalamic area neurotensin neurons to inhibit orexin neurons by multiple GABA-independent mechanisms., J. Neurosci. 34 (2014) 11405-15. doi:10.1523/JNEUROSCI.5167-13.2014.

[62] G.M. Leinninger, D.M. Opland, Y.-H. Jo, M. Faouzi, L. Christensen, L.A. Cappellucci, C.J. Rhodes, M.E. Gnegy, J.B. Becker, E.N. Pothos, A.F. Seasholtz, R.C. Thompson, M.G. Myers, Leptin action via neurotensin neurons controls orexin, the mesolimbic dopamine system and energy balance., Cell Metab. 14 (2011) 313-23. doi:10.1016/j.cmet.2011.06.016.

[63] H. Cui, J.-W. Sohn, L. Gautron, H. Funahashi, K.W. Williams, J.K. Elmquist, M. Lutter, Neuroanatomy of melanocortin-4 receptor pathway in the lateral hypothalamic area, J. Comp. Neurol. 520 (2012) 4168-4183. doi:10.1002/cne.23145.

[64] C.F. Elias, C.B. Saper, E. Maratos-Flier, N.A. Tritos, C. Lee, J. Kelly, J.B. Tatro, G.E. Hoffman, M.M. Ollmann, G.S. Barsh, T. Sakurai, M. Yanagisawa, J.K. Elmquist, Chemically defined projections linking the mediobasal hypothalamus 
and the lateral hypothalamic area., J. Comp. Neurol. 402 (1998) 442-59. doi:10.1002/(SICI)1096-9861(19981228)402:4<442::AID-CNE2>3.0.CO;2-R.

[65] P.B. Goforth, M.G. Myers, Roles for orexin/hypocretin in the control of energy balance and metabolism., Curr. Top. Behav. Neurosci. 33 (2016) 137-156. doi:10.1007/7854_2016_51.

[66] K. Toshinai, Y. Date, N. Murakami, M. Shimada, M.S. Mondal, T. Shimbara, J.L. Guan, Q.-P. Wang, H. Funahashi, T. Sakurai, S. Shioda, S. Matsukura, K. Kangawa, M. Nakazato, Ghrelin-induced food intake is mediated via the orexin pathway., Endocrinology. 144 (2003) 1506-12. doi:10.1210/en.2002-220788.

[67] A. Yamanaka, C.T. Beuckmann, J.T. Willie, J. Hara, N. Tsujino, M. Mieda, M. Tominaga, K. ichi Yagami, F. Sugiyama, K. Goto, M. Yanagisawa, T. Sakurai, Hypothalamic orexin neurons regulate arousal according to energy balance in mice., Neuron. 38 (2003) 701-13. doi:10.1016/S0896-6273(03)00331-3.

[68] M.R. Jain, T.L. Horvath, P.S. Kalra, S.P. Kalra, Evidence that NPY Y1 receptors are involved in stimulation of feeding by orexins (hypocretins) in sated rats, Regul. Pept. 87 (2000) 19-24.

[69] G. Morello, R. Imperatore, L. Palomba, C. Finelli, G. Labruna, F. Pasanisi, L. Sacchetti, L. Buono, F. Piscitelli, P. Orlando, V. Di Marzo, L. Cristino, Orexin-A represses satiety-inducing POMC neurons and contributes to obesity via stimulation of endocannabinoid signaling., Proc. Natl. Acad. Sci. U. S. A. 113 (2016) 4759-64. doi:10.1073/pnas.1521304113.

[70] H. Yamada, T. Okumura, W. Motomura, Y. Kobayashi, Y. Kohgo, Inhibition of food intake by central injection of anti-orexin antibody in fasted rats., Biochem. Biophys. Res. Commun. 267 (2000) 527-31. doi:10.1006/bbrc.1999.1998. 
[71] X. Ma, L. Zubcevic, J.C. Brüning, F.M. Ashcroft, D. Burdakov, Electrical inhibition of identified anorexigenic POMC neurons by orexin/hypocretin., J. Neurosci. 27 (2007) 1529-33. doi:10.1523/JNEUROSCI.3583-06.2007.

[72] D. Kohno, H.-Z. Gao, S. Muroya, S. Kikuyama, T. Yada, Ghrelin directly interacts with neuropeptide-Y-containing neurons in the rat arcuate nucleus: $\mathrm{Ca} 2+$ signaling via protein kinase $\mathrm{A}$ and $\mathrm{N}$-type channel-dependent mechanisms and cross-talk with leptin and orexin., Diabetes. 52 (2003) 948-56. doi:10.2337/diabetes.52.4.948.

[73] S. Muroya, H. Funahashi, A. Yamanaka, D. Kohno, K. Uramura, T. Nambu, M. Shibahara, M. Kuramochi, M. Takigawa, M. Yanagisawa, T. Sakurai, S. Shioda, T. Yada, Orexins (hypocretins) directly interact with neuropeptide Y, POMC and glucose-responsive neurons to regulate $\mathrm{Ca} 2+$ signaling in a reciprocal manner to leptin: orexigenic neuronal pathways in the mediobasal hypothalamus., Eur. J. Neurosci. 19 (2004) 1524-34. doi:10.1111/j.1460-9568.2004.03255.x.

[74] Y. Date, Y. Ueta, H. Yamashita, H. Yamaguchi, S. Matsukura, K. Kangawa, T. Sakurai, M. Yanagisawa, M. Nakazato, Orexins, orexigenic hypothalamic peptides, interact with autonomic, neuroendocrine and neuroregulatory systems., Proc. Natl. Acad. Sci. U. S. A. 96 (1999) 748-53.

[75] T.C. Kirkham, C.M. Williams, F. Fezza, V. Di Marzo, Endocannabinoid levels in rat limbic forebrain and hypothalamus in relation to fasting, feeding and satiation: stimulation of eating by 2-arachidonoyl glycerol., Br. J. Pharmacol. 136 (2002) 550-7. doi:10.1038/sj.bjp.0704767.

[76] C. Ravinet Trillou, M. Arnone, C. Delgorge, N. Gonalons, P. Keane, J.-P. Maffrand, P. Soubrie, Anti-obesity effect of SR141716, a CB1 receptor 
antagonist, in diet-induced obese mice., Am. J. Physiol. Regul. Integr. Comp. Physiol. 284 (2003) R345-53. doi:10.1152/ajpregu.00545.2002.

[77] V. Di Marzo, S.K. Goparaju, L. Wang, J. Liu, S. Bátkai, Z. Járai, F. Fezza, G.I. Miura, R.D. Palmiter, T. Sugiura, G. Kunos, Leptin-regulated endocannabinoids are involved in maintaining food intake., Nature. 410 (2001) 822-5. doi:10.1038/35071088.

[78] H. Huang, C. Acuna-Goycolea, Y. Li, H.M. Cheng, K. Obrietan, A.N. van den Pol, Cannabinoids excite hypothalamic melanin-concentrating hormone but inhibit hypocretin/orexin neurons: implications for cannabinoid actions on food intake and cognitive arousal., J. Neurosci. 27 (2007) 4870-81. doi:10.1523/JNEUROSCI.0732-07.2007.

[79] I. Crespo, R. Gómez de Heras, F. Rodríguez de Fonseca, M. Navarro, Pretreatment with subeffective doses of Rimonabant attenuates orexigenic actions of orexin A-hypocretin 1, Neuropharmacology. 54 (2008) 219-225. doi:10.1016/j.neuropharm.2007.05.027.

[80] I. Merroun, N. El Mlili, R. Martinez, JM. Porres, J. Llopis, H. Ahabrach, P. Aranda, C. Sanchez Gonzalez, M. Errami, M. Lopez-Jurado, Interaction between orexin A and cannabinoid system in the lateral hypothalamus of rats and effects of subchronic intraperitoneal administration of cannabinoid receptor inverse agonist on food intake and the nutritive utilization of protein. J. Physiol. Pharmacol. 66 (2015) 181-190.

[81] L. Cristino, G. Busetto, R. Imperatore, I. Ferrandino, L. Palomba, C. Silvestri, S. Petrosino, P. Orlando, M. Bentivoglio, K. Mackie, V. Di Marzo, Obesity-driven synaptic remodeling affects endocannabinoid control of orexinergic neurons., 
Proc. Natl. Acad. Sci. U. S. A. 110 (2013) E2229-38.

doi:10.1073/pnas.1219485110.

[82] T.M. Becker, M. Favero, V. Di Marzo, L. Cristino, G. Busetto,

Endocannabinoid-dependent disinhibition of orexinergic neurons:

Electrophysiological evidence in leptin-knockout obese mice., Mol. Metab. 6 (2017) 594-601. doi:10.1016/j.molmet.2017.04.005.

[83] H. Tsuneki, T. Wada, T. Sasaoka, Role of orexin in the regulation of glucose homeostasis, in: Acta Physiol., 2010: pp. 335-348. doi:10.1111/j.17481716.2009.02008.x

[84] H. Funato, A.L. Tsai, J.T. Willie, Y. Kisanuki, S.C. Williams, T. Sakurai, M. Yanagisawa, Enhanced orexin receptor-2 signaling prevents diet-induced obesity and improves leptin sensitivity., Cell Metab. 9 (2009) 64-76. doi:10.1016/j.cmet.2008.10.010.

[85] J.A. González, L.T. Jensen, P. Iordanidou, M. Strom, L. Fugger, D. Burdakov, Inhibitory interplay between orexin neurons and eating., Curr. Biol. 26 (2016) 2486-2491. doi:10.1016/j.cub.2016.07.013.

[86] X.-B. Gao, T.L. Horvath, Feeding Behavior: Hypocretin/Orexin neurons act between food seeking and eating., Curr. Biol. 26 (2016) R845-R847. doi:10.1016/j.cub.2016.07.069.

[87] V. Di Marzo, I. Matias, Endocannabinoid control of food intake and energy balance., Nat. Neurosci. 8 (2005) 585-9. doi:10.1038/nn1457.

[88] D. Yang, L. Xu, F. Guo, X. Sun, D. Zhang, M. Wang, Orexin-A and endocannabinoid signaling regulate glucose-responsive arcuate nucleus neurons 
and feeding behavior in obese rats, Neuropeptides. (2018).

doi:10.1016/j.npep.2018.04.001.

[89] K. Ren, R. Dubner, Neuron-glia crosstalk gets serious: role in pain hypersensitivity., Curr. Opin. Anaesthesiol. 21 (2008) 570-9. doi:10.1097/ACO.0b013e32830edbdf.

[90] Y.-C. Ho, H.-J. Lee, L.-W. Tung, Y.-Y. Liao, S.-Y. Fu, S.-F. Teng, H.-T. Liao, K. Mackie, L.-C. Chiou, Activation of orexin 1 receptors in the periaqueductal gray of male rats leads to antinociception via retrograde endocannabinoid (2arachidonoylglycerol)-induced disinhibition., J. Neurosci. 31 (2011) 14600-10. doi:10.1523/JNEUROSCI.2671-11.2011.

[91] A.G. Hohmann, R.L. Suplita, N.M. Bolton, M.H. Neely, D. Fegley, R. Mangieri, J.F. Krey, J.M. Walker, P. V Holmes, J.D. Crystal, A. Duranti, A. Tontini, M. Mor, G. Tarzia, D. Piomelli, An endocannabinoid mechanism for stress-induced analgesia., Nature. 435 (2005) 1108-12. doi:10.1038/nature03658.

[92] M.H. Esmaeili, Z. Reisi, S. Ezzatpanah, A. Haghparast, Functional interaction between orexin-1 and $\mathrm{CB} 1$ receptors in the periaqueductal gray matter during antinociception induced by chemical stimulation of the lateral hypothalamus in rats., Eur. J. Pain. 20 (2016) 1753-1762. doi:10.1002/ejp.899.

[93] M.-H. Esmaeili, Z. Reisi, S. Ezzatpanah, A. Haghparast, Role of orexin-2 and CB1 receptors within the periaqueductal gray matter in lateral hypothalamicinduced antinociception in rats., Behav. Pharmacol. 28 (2017) 83-89. doi:10.1097/FBP.0000000000000277.

[94] H. Mohammad-Pour Kargar, H. Azizi, J. Mirnajafi-Zadeh, M. Ali Reza, S. Semnanian, Microinjection of orexin-A into the rat locus coeruleus nucleus 
induces analgesia via cannabinoid type-1 receptors., Brain Res. 1624 (2015) 424432. doi:10.1016/j.brainres.2015.07.050.

[95] L. Cristino, L. Luongo, R. Imperatore, S. Boccella, T. Becker, G. Morello, F. Piscitelli, G. Busetto, S. Maione, V. Di Marzo, Orexin-A and endocannabinoid activation of the descending antinociceptive pathway underlies altered pain perception in leptin signaling deficiency., Neuropsychopharmacology. 41 (2016) 508-20. doi:10.1038/npp.2015.173.

[96] M.H. James, S. V. Mahler, D.E. Moorman, G. Aston-Jones, A decade of orexin/hypocretin and addiction: Where are we now?, Curr. Top. Behav. Neurosci. 33 (2017) 247-281. doi:10.1007/7854_2016_57.

[97] R.A. España, J.R. Melchior, D.C.S. Roberts, S.R. Jones, Hypocretin 1/orexin A in the ventral tegmental area enhances dopamine responses to cocaine and promotes cocaine self-administration., Psychopharmacology (Berl). 214 (2011) 415-26. doi:10.1007/s00213-010-2048-8.

[98] T.M. Korotkova, O.A. Sergeeva, K.S. Eriksson, H.L. Haas, R.E. Brown, Excitation of ventral tegmental area dopaminergic and nondopaminergic neurons by orexins/hypocretins., J. Neurosci. 23 (2003) 7-11. doi:10.1523/JNEUROSCI.23-01-00007.2003.

[99] S.L. Borgland, S.A. Taha, F. Sarti, H.L. Fields, A. Bonci, Orexin A in the VTA is critical for the induction of synaptic plasticity and behavioral sensitization to cocaine., Neuron. 49 (2006) 589-601. doi:10.1016/j.neuron.2006.01.016.

[100] C. Baimel, S.L. Borgland, Orexin signaling in the VTA gates morphine-induced synaptic plasticity., J. Neurosci. 35 (2015) 7295-303. doi:10.1523/JNEUROSCI.4385-14.2015. 
[101] M.E. Sloan, J.L. Gowin, V.A. Ramchandani, Y.L. Hurd, B. Le Foll, The endocannabinoid system as a target for addiction treatment: Trials and tribulations., Neuropharmacology. 124 (2017) 73-83. doi:10.1016/j.neuropharm.2017.05.031.

[102] A.C. Riegel, C.R. Lupica, Independent presynaptic and postsynaptic mechanisms regulate endocannabinoid signaling at multiple synapses in the ventral tegmental area., J. Neurosci. 24 (2004) 11070-8. doi:10.1523/JNEUROSCI.3695-04.2004.

[103] M. Melis, M. Pistis, S. Perra, A.L. Muntoni, G. Pillolla, G.L. Gessa, Endocannabinoids mediate presynaptic inhibition of glutamatergic transmission in rat ventral tegmental area dopamine neurons through activation of CB1 receptors, J. Neurosci. 24 (2004) 53-62. doi:10.1523/JNEUROSCI.450303.2004 .

[104] L.-W. Tung, G.-L. Lu, Y.-H. Lee, L. Yu, H.-J. Lee, E. Leishman, H. Bradshaw, L.-L. Hwang, M.-S. Hung, K. Mackie, A. Zimmer, L.-C. Chiou, Orexins contribute to restraint stress-induced cocaine relapse by endocannabinoidmediated disinhibition of dopaminergic neurons., Nat. Commun. 7 (2016) 12199. doi:10.1038/ncomms12199.

[105] Z. Taslimi, A. Haghparast, M. Hassanpour-Ezatti, M.-S. Safari, Chemical stimulation of the lateral hypothalamus induces conditioned place preference in rats: Involvement of $\mathrm{OX} 1$ and $\mathrm{CB} 1$ receptors in the ventral tegmental area., Behav. Brain Res. 217 (2011) 41-6. doi:10.1016/j.bbr.2010.10.007.

[106] Z. Fatahi, N. Assar, D. Mahmoudi, P. Pahlevani, M. Moradi, A. Haghparast, Functional interaction between the orexin-1 and CB1 receptors within the nucleus accumbens in the conditioned place preference induced by the lateral 
hypothalamus stimulation., Pharmacol. Biochem. Behav. 132 (2015) 42-48. doi:10.1016/j.pbb.2015.02.023.

[107] F. Yazdi, M. Jahangirvand, A.-H. Pirasteh, M. Moradi, A. Haghparast, Functional interaction between $\mathrm{OX} 2$ and $\mathrm{CB} 1$ receptors in the ventral tegmental area and the nucleus accumbens in response to place preference induced by chemical stimulation of the lateral hypothalamus., Pharmacol. Biochem. Behav. 139 (2015) 39-46. doi:10.1016/j.pbb.2015.10.012.

[108] F. Azizi , R. Fartootzadeh, H. Alaei, P. Reisi, Effects of concurrent blockade of $\mathrm{OX} 2$ and $\mathrm{CB} 1$ receptors in the ventral tegmental area on nicotine-induced place preference in rats. Neurosci. Lett. 684 (2018) 121-126. doi: 10.1016/j.neulet.2018.07.017.

[109] M. Melis, R. Frau, P.W. Kalivas, S. Spencer, V. Chioma, E. Zamberletti, T. Rubino, D. Parolaro, New vistas on cannabis use disorder., Neuropharmacology. 124 (2017) 62-72. doi:10.1016/j.neuropharm.2017.03.033.

[110] R. Vandrey, M. Haney, Pharmacotherapy for cannabis dependence: how close are we?, CNS Drugs. 23 (2009) 543-53. doi:10.2165/00023210-200923070-00001.

[111] A. Rotter, K. Bayerlein, M. Hansbauer, J. Weiland, W. Sperling, J. Kornhuber, T. Biermann, Orexin A expression and promoter methylation in patients with cannabis dependence in comparison to nicotine-dependent cigarette smokers and nonsmokers., Neuropsychobiology. 66 (2012) 126-33. doi:10.1159/000339457.

[112] Á. Flores, R. Maldonado, F. Berrendero, The hypocretin/orexin receptor-1 as a novel target to modulate cannabinoid reward., Biol. Psychiatry. 75 (2014) 499507. doi:10.1016/j.biopsych.2013.06.012. 
[113] Á. Flores, M. Julià-Hernández, R. Maldonado, F. Berrendero, Involvement of the orexin/hypocretin system in the pharmacological effects induced by $\Delta(9)$ tetrahydrocannabinol., Br. J. Pharmacol. 173 (2016) 1381-92. doi:10.1111/bph.13440. 


\section{Figure 1. Orexins repress neuronal activity through endocannabinoid signaling.}

Upon orexin release, activation of postsynaptic OX1R leads to biosynthesis of the endocannabinoid 2-arachidonoylglycerol (2-AG) through a Gq-protein-phospholipase C- diacylglycerol lipase (PLC-DAGL) cascade. 2-AG diffuses to the extracellular space and activates CB1R present in surrounding cells, producing hyperpolarization of the neuronal membrane and inhibiting subsequent neurotransmitter release at the axon terminal. This mechanism has functional consequences at diverse orexinergic target sites: 1. Within the ventral tegmental area (VTA), OX1R-induced 2-AG release leads to inhibition of GABAergic interneurons and subsequent disinhibition of dopaminergic neurons, contributing to cocaine relapse; 2. In the arcuate nucleus (ARC), POMC neurons are retrogradely inhibited by their own OX1R-induced 2-AG generation, this leads to diminished satiety signaling, producing hyperphagia and contributing to obesity; 3. Within the periaqueductal gray (PAG) GABAergic interneurons are also inhibited by $2-A G$ release, resulting in disinhibition of non-determined antinociceptive pathways. PIP2, phosphatidylinositol 4,5-bisphosphate; DAG, diacylglycerol; NT, neurotransmitter; OX, orexin neurons; LH, lateral hypothalamus.
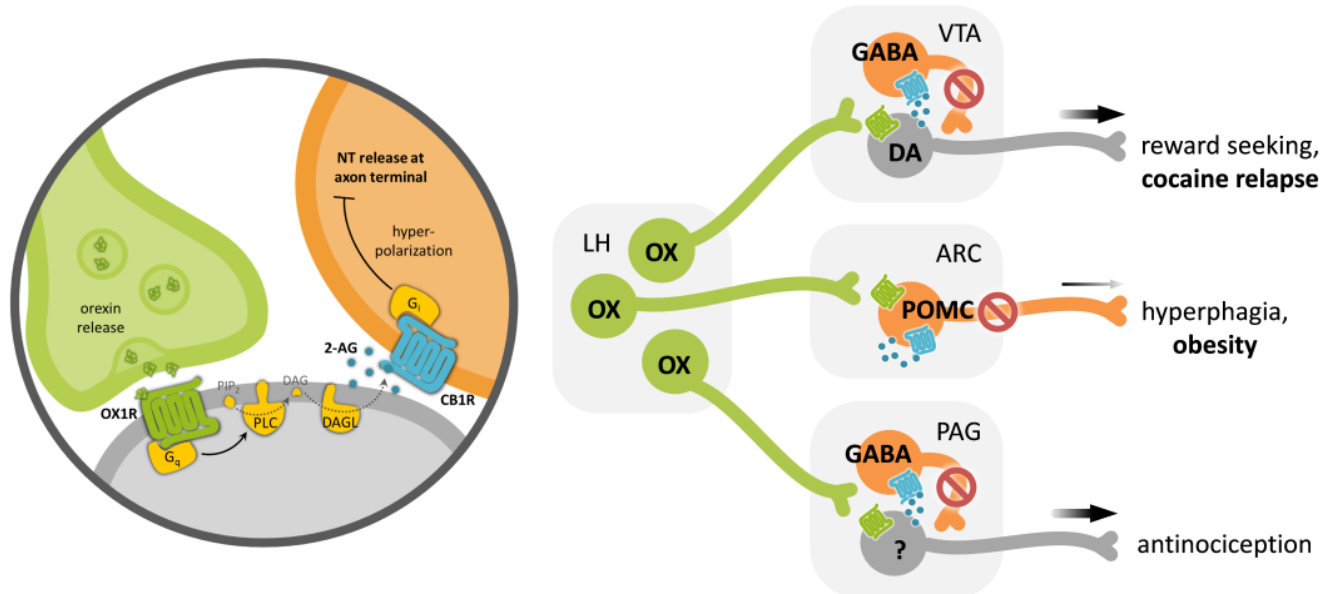


\section{Figure 2. Orexinergic modulation of cannabinoid-induced behavioral effects.}

Exogenous cannabinoids, such as THC or WIN55, 212-2, produce a series of behavioral responses, presumably through CB1R. Some of these responses are independent of orexin transmission, including hypolocomotion, anxiogenic-like and amnesic-like effects. However, antinociception, hypothermia and anxiolytic-like responses are modulated by OX2R signaling. Besides, OX1R stimulation contributes to cannabinoidinduced reinforcement. This implies that selective OX1R antagonists could be employed as a therapeutic tool to prevent the potential abuse liability associated to cannabinoid-based therapies, while preserving their beneficial effects.






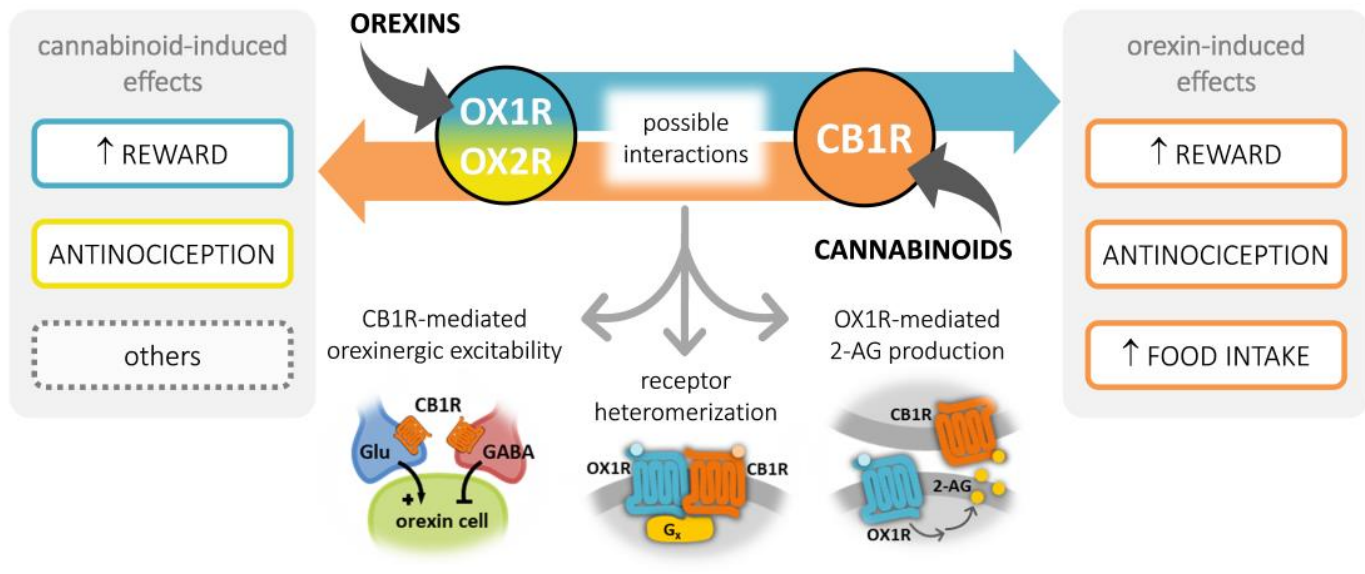

